\title{
In Silico Prediction of The Antiangiogenesis Activity of Heliannuol Lactone sesquiterpenes Compounds from Sunflower (Heliannthus annuus L.)
}

\author{
Roihatul Muti'ah ${ }^{1}$, Alif Firman Firdausy ${ }^{2}$, Tanaya Jati Dharma Dewi ${ }^{3}$, Eka Kartini Rahmawati ${ }^{4}$ \\ Department of Pharmacy, Faculty of Medical and Health Sciences, \\ Maulana Malik Ibrahim State Islamic University of Malang, Indonesia
}

\begin{abstract}
Heliannuols are sesquiterpenes lactone compounds considered to have anticancer activity on the brain cancer. Cancer cell growth is related to overexpression of Vascular Endothelial Growth Factor Receptor-2 (VEGFR-2) as a pro-angiogenic pathway, which becomes the main factor of angiogenesis and progression. This research aims to predict anti-angiogenic, toxicity, and physicochemical properties of heliannuols. Physicochemical properties were predicted referred to Lipinski's rule of five (Lipinski RO5), while absorption, distribution, metabolism, and excretion were predicted by using pkCSM online tool. The toxicity of compounds was predicted by using Protox II online tool, and interaction of the ligand with receptors was predicted by conducting validation (VEGFR-2 (PDB ID: 3WZE)) and molecular docking using Molegro Virtual Docker (MVD). The result revealed that Lipinski RO5 compatible heliannuols had the lowest $L_{50} 2148 \mathrm{mg} / \mathrm{kg}$ predictive $L_{50}$ predictive values of heliannuol $\mathrm{D}$. The docking result was described by rerank score (RS), representing the bound energy form and compares with Sorafenib as a reference drug. Five medium strength VEGFR-2 chemical substances with rerank score: heliannuol A -56.9496, heliannuol heliannuol B -70.83646, heliannuol C -61,3292, heliannuol D -49.61646, and heliannuol E -75.5164. No better rerank score was recorded for all inhibitors than sorafenib (-128.0683). The heliannuols interacted with amino acid residues Glu885 and Asp1046 that probably conferred the antiangiogenic activity. Taken together, heliannuol D had the greates activity to the target protein and complied Lipinski RO5.
\end{abstract}

Keywords: anti-angiogenic, toxicity, heliannuol, VEGFR-2, brain cancer, molecular docking.

\section{INTRODUCTION}

Brain cancer is an abnormal mass in the body caused by excessive multiplication of cells and causes the process of space pressure (Talo, et al., 2019). Brain cancer is the third leading cause of death at the age of under the age of 20 years and the age of 20-39 (Ministry of Health, 2017). The global incidence of brain cancer is 4.25 cases in 100,000 people (Bell, et al., 2019).
Surgery, chemotherapy and radiotherapy are intensive treatment efforts. However, these treatments have not been able effectively to tackle cancer (Conze, 2001). Therefore, it is necessary to

Submitted: September 22, 2020

Revised: August 26, 2021

Accepted: August 26, 2021

*Corresponding author: roiha@farmasi.uin-malang.ac.id 
develop anticancer drugs using natural substance. Components predict to have chemopreventive agent activity are heliannuol which is contained in Helianthus annuus and belongs to the lactone sesquiterpenes class. Heliannuol compounds are reported to be able to cross the blood brain barrier (BBB) in the in silico physicochemical properties study (Firdausy, et al., 2020). The BBB being the tightest endothelium in the body also represents the main impediment to drug delivery to the brain (Bellettato and Scarpa, 2018). Therapeutic targeting of the BBB is emerging as critically relevant clinical goal such as brain cancer (Agarwal, et al., 2011; Kesari, 2011; Nico, 2012).

Inhibition of the Nuclear Factor-kB (NF$\mathrm{kB}$ ) signaling pathway is one of the anticancer mechanisms in sesquiterpene lactone compounds (Babei, et al., 2018). NF-kB has a major role in inhibiting apoptosis, induction of metastasis, cell proliferation, cell transformation, invasion, metastasis, resistance to chemotherapy, and resistance to radiotherapy (Jeroen, et al., 2007; Kreunger, et al., 2012). Some heliannuol compounds have benzoxepine rings, where only refer to place the ring has anticancer activity through inhibition of Phosphoinoside 3-kinase (PI3K). Researchers have explored this class of heterocycles as potential anticancer agents. The benzoxepine ring seemed would able to grant acces to Agr770 and Ser773 (Heffron, et al., 2011; Kuntala, et al., 2017). By inhibiting the receptor, Vascular Endothelial Growth Factor Receptor-2 (VEGFR-2) will inhibit all signaling pathways (PDB ID: 3WZE). The Both signaling pathways can be inhibited by inhibiting the receptor Vascular Endothelial Growth Factor Receptor-2 (VEGFR-2) (PDB ID: 3WZE).

Thus, the disorderly tumor vasculature observed in the tumors significantly changes the microenvironment of the tumor and affects multiple aspects of tumor proliferation, such as tumor formation, enabling the tumor cells to quickly infiltrate and metastasize to distant locations. One of the functional approaches to inhibiting tumor angiogenesis is to recognize the role of angiogenesis in tumor vasculature and inhibition of growth factors/signaling pathways essential for endothelial cell growth and proliferation.

Tumors generate abnormal and functionally immature blood vessels due to deregulated factors such angiogenic growth factor, angiogenesis inhibitor, and other genetic factors by a process known as pathological angiogenesis (Carmeliet and Jain, 2011). Blood vessels developing in the primary tumor are larger than their normal counterparts and follow a criss-cross path, with irregular lumen diameters, dilated, highly permeable and branch irregulary (De Bock, et al., 2011). The selection of these receptors to block activators of angiogenesis is crucial in the field of brain anticancer drug discovery which plays a significant role in modulet vessel permeability, remodeling, endothelial cell survival, proliferation and migration (Knizetova, et al., 2008). The rational behind antiangiogenic thearphy is the concept that blocking blood vessel formation in cancer or its regression would deprive cancer cells of nutrients and oxygen and finally starve to death or induce tumor dormancy. In this study, the researcher performs the prediction of the physicochemical properties, toxicity and antiangiogenic activity of the heliannuols compound to VEGFR-2 (PDB ID: 3WZE).

\section{METHOD AND MATERIALS}

\section{Software}

The software used include 3D ChemBio program package v.12.0.2 Free Trial (serial number: 186-410320-7811). The program pkCSM Online Tool (Prediction of Pramacokinetics Properties Online Tool 2015 by Douglas (http://structure.bioc. cam.ac.uk/ pkcsm). The program Protox II Online Tool (http://accelrys.com/). Molegro Virtual Docker (MVD 2013.6.0) program (fully functional, free trial version with time limiting license; Molegro Virtual Docker (MVD 2013.6.0). 


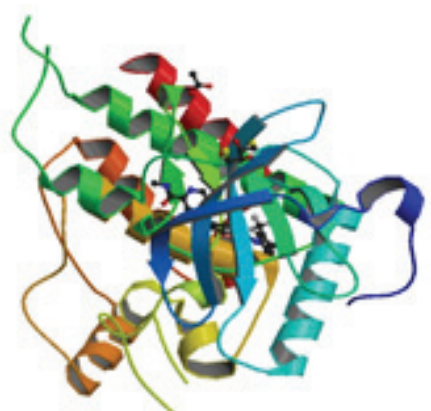

Figure 1. Receptor of VEGFR-2 (PDB ID: 3WZE).

The study began with the preparation of VEGFR-2 (PDB code: 3WZE) obtained from the Protein Data Bank (www.pdb.org). The preparation was done by downloading data from PDB 3WZE, reducting $3 \mathrm{WZE}$ chains into monomeric form using SwissPDBViewer v4.1, analysis binding pocket by Ligand Explorer Viewer bond in Protein Data Bank (www.pdb.org). and Q-siteFinder, analysis of ligand-receptor interactions with the Ligan Explorer Viewer in the Protein Data Bank (www.pdb.org).

Subsequently, preparation of ligand heliannuols were done by 3D ChemBio package v.12.0.2 Free Trial. The ligand preparation was started by drawing 2D and 3D ligand structure using ChemBio program package 3D v.12.0.2 Free Trial.

\section{Target and Template Selection}

PDB ID of VEGFR-2:3WZE with resolution $1.90 \AA$ was obtained from protein Data Bank (https://www.rcsb. org). The SMILES code was obtained from PubChem Compound (https:// pubchem.ncbi.nlm.nih.gov/).

\section{Prediction of Physicochemical Properties and Toxicity}

The SMILE code and the pkCSM online tool were used to predict physicochemical properties and toxicity, and then they were estimated based on the Lipinski Law of Five. The online tool Protox II was used for toxicity.

\section{Molecular Docking Study}

Using the MVD software, docking and amino acid analysis was carried out. The protocol for docking the measures is as follows: Docking and amino acids analysis were performed using the MVD program. The steps for docking process as follows: Selection of proteins target: The PDB ID is 3WZE. Determination of bonding position: The protein active sites was determined based on the ligand positions within a radius of $4.5 \AA$ and the presence of important amino acids. Creating 3D structures: The 2D chemical structure (flat structure) of the compounds was automatically converted to the 3D chemical structure (three-dimensional structure) by ChemBio Ultra software. Lowestenergy state: The 3D molecular structures of the compounds were then optimized using MMFF94 method using the same software. Preparation of docks of molecules in protein and simulation. Docking compounds into prepared proteins and compounds via the MVD program docking process with the following options: Moldoc Score [Column], Grid resolution 0.3; Ligand assessment: Internal ES, Internal Hbond, Sp2-Sp2 Torsion, MolDock SE alogarithm, minimization of energy and optimization after docking of hydrogen bonds. The interaction analysis of compounds and targeted proteins. Different associations are plotted, such as van der Waals interactions, hydrogen bonds, cation- $\pi$ bonds, $\pi-\pi$ bonds, and ionic interactions, and the gap of contact between amino acids and compound active sites. Van der Waals interactions was detected by contact with hydrophilic and hydrophobic surfaces between the compounds and the bonding point.

\section{RESULTS}

\section{Prediction of Physicochemical Properties and Toxicity}

The result of absorption, permeability and toxicity prediction of heliannuols using Lipinski's rules of five showed that the four physicochemical 
properties were $\log p<5$, molecular weight $<500, \mathrm{H}$ bond donor $<5$ and $\mathrm{H}$ bond acceptor $<10$ (Lipinski, et al., 2001). Based on these results, the five heliannuols met the Lipinski's five rules in order to predict that, for example, heliannuol will work on effectiveness, protection or metabolism. Furthermore, small molecules of drug candidates and chemical samples must be properly tested to meet their site of operation and to accomplish the primary objective. Table 1 shows the predicted results of physicochemical properties and toxicity.

\section{Receptor Validation}

Receptor validation was conducted to evaluate whether the 3 WZE receptor was suitable for docking or not. Receptor validation using Molegro Virtual Docker 6.0 was done by redocking receptor cavity native ligands resulting from the receptor validation process, namely the RMSD (Root Mean Square Deviation) value with an ideal value $<2 \AA$ (Pratama, 2015). The results of receptor validation are shown in Table 2 and the best positions of ligands and receptors are shown in Figure 2.

\section{Docking Molecular and Interaction}

Prediction of antiangiogenic activity was done by docking heliannuol A-E compounds with Vascular Endothelial Growth Factor (VEGFR-2) (3WZE) receptors which were previously validated by receptors by redocking molecules to select the most ideal chain. The selection of this chain is seen from the results of the RMSD values obtained in the redocking process. The RMSD value less than $2 \AA$ is considered to have performed successfully and was found that poses reseptor with native ligand has valid (Pratama, 2015). Based on the validation results of the 3 WZE receptors mentioned in Table 2, an RMSD value of 0.285606 is accurate for docking simulations performed on BAX-1202 or $\mathrm{N}$-methylpyridine-2-carboxamide native ligands. Whereas in cavity 1 the RMSD value is 11.5391 (more than 2), so that is used for molecular docking at BAX-1202 cavity 2 .

The rerank score used in MVD is a weighted combination of the terms used by the MolDOck score mixed with a few addition terms which includes the steric term which are Lennard Jones approximations to the steric energy

Table 1. Prediction of physical and chemical properties and toxicity.

\begin{tabular}{|c|c|c|c|c|c|c|}
\hline No & Compound & Formula & Structure & $\begin{array}{l}\text { Toxicity } \\
\text { LD } 50\end{array}$ & \multicolumn{2}{|c|}{$\begin{array}{l}\text { Lipinski } \\
\text { rules of five }\end{array}$} \\
\hline I & $\begin{array}{c}\text { Heliannuol A } \\
{[\mathrm{HA}]}\end{array}$ & $\mathrm{C}_{15} \mathrm{H}_{22} \mathrm{O}_{3}$ & & 860 mg/kg & $\begin{array}{l}\text { MW } \\
\text { Log P } \\
\text { HBD } \\
\text { HBA } \\
\text { PSA }\end{array}$ & $\begin{array}{l}250.338 \\
3.116 \\
2 \\
3 \\
108.412\end{array}$ \\
\hline 2 & $\begin{array}{c}\text { Heliannuol B } \\
{[\mathrm{HB}]}\end{array}$ & $\mathrm{C}_{15} \mathrm{H}_{20} \mathrm{O}_{3}$ & & 482 mg/kg & $\begin{array}{l}\text { MW } \\
\text { Log P } \\
\text { HBD } \\
\text { HBA } \\
\text { PSA }\end{array}$ & $\begin{array}{l}248.322 \\
2.892 \\
2 \\
3 \\
107.722\end{array}$ \\
\hline 3 & $\begin{array}{c}\text { Heliannuol C } \\
{[\mathrm{HC}]}\end{array}$ & $\mathrm{C}_{15} \mathrm{H}_{20} \mathrm{O}_{3}$ & & 500 mg/kg & $\begin{array}{l}\text { MW } \\
\text { Log P } \\
\text { HBD } \\
\text { HBA } \\
\text { PSA }\end{array}$ & $\begin{array}{l}248.322 \\
2.892 \\
2 \\
3 \\
107.722\end{array}$ \\
\hline 4 & $\begin{array}{l}\text { Heliannuol D } \\
\text { [HD] }\end{array}$ & $\mathrm{C}_{15} \mathrm{H}_{22} \mathrm{O}_{3}$ & & $2148 \mathrm{mg} / \mathrm{kg}$ & $\begin{array}{l}\text { MW } \\
\text { Log P } \\
\text { HBD } \\
\text { HBA } \\
\text { PSA }\end{array}$ & $\begin{array}{l}250.338 \\
3.116 \\
2 \\
3 \\
108.412\end{array}$ \\
\hline 5 & $\begin{array}{c}\text { Heliannuol E } \\
{[\mathrm{HE}]}\end{array}$ & $\mathrm{C}_{15} \mathrm{H}_{20} \mathrm{O}_{3}$ & & $500 \mathrm{mg} / \mathrm{kg}$ & $\begin{array}{l}\text { MW } \\
\text { Log P } \\
\text { HBD } \\
\text { HBA } \\
\text { PSA }\end{array}$ & $\begin{array}{l}248.332 \\
2.892 \\
2 \\
3 \\
107.722\end{array}$ \\
\hline
\end{tabular}


Table 2. VEGFR-2 (3WZE) receptor validation results.

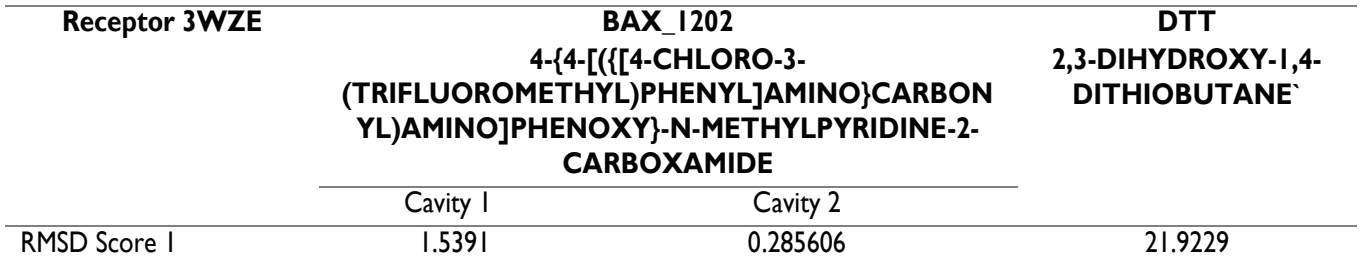

(Thomsen R, 2006). The reranking score function is computationally more expensive than scoring function used during the docking simulation, but it generally gives better result than docking score function. The reranking coefficients used the energy parameters such as E-Inter total, E-Inter (proteinligand), steric, VdW (Van de Waal's), Hbond, E-Intra (tors, ligand atoms), E-Solvation, E-Total etc. In addition as shown in Figure 2, heliannuols $\mathrm{B}$, heliannuol $\mathrm{C}$ and Sorafenib were found to be lying deep inside the binding pocket of Glu885 and Asp1046which is an andication of a strong molecular interaction exhibiting both bonded and non bonded interaction.

Comparison of the amino acid residues of the active pocket $3 \mathrm{WZE}$ using MVD and can be seen in Table 3. Table 3 showed the similarity of amino acid residues that were known by MVD. Its analysis was based on the principle of the interaction energy between macromolecules with a van der Waals loop to fi pockets that are considered the most favored binding by the ligand from the energy point of view (ie, pocket bonding interactions lowest energy).

A.

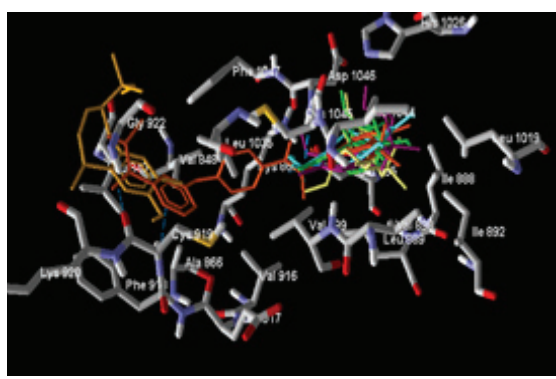

\section{DISSCUSSION}

This study aims to predict the physicochemical, toxicity, and antiangiogenesis properties of heliannuols. Several rules are developed in order to guide the selection of compounds in the early phase of drug discovery or to prepare the chemical compounds. Among the first applications of physicochemical properties in drug discovery, the rule of five (RO5) was formulated in 1997 by Lipinski and colleagues (Lipinski, et al., 2001). The RO5 states that a compound is more likely to be membrane permeable and easly absorbed via passive diffusion in human intestine if it matches the following criteria $\log -P \leq 5 ; \mathrm{MW} \leq 500 ; \mathrm{HBA}(\mathrm{O}+\mathrm{N}$ atom count $) \leq 10$ and HBDs $\mathrm{OH}+\mathrm{NH}$ count $) \leq 5$.

Lipinski's RO5 have been met by the five test compounds, heliannuol A-E, so that the test compounds can be expected to have strong absorption and permeability. As a consequence of the measurement of molecular weight, the compound heliannuol AE has been found to have a meaning in the recommended range with a molecular weight of less than $500 \mathrm{Da}$ and a molecular weight of $\mathrm{HB}=\mathrm{H}-$

B.

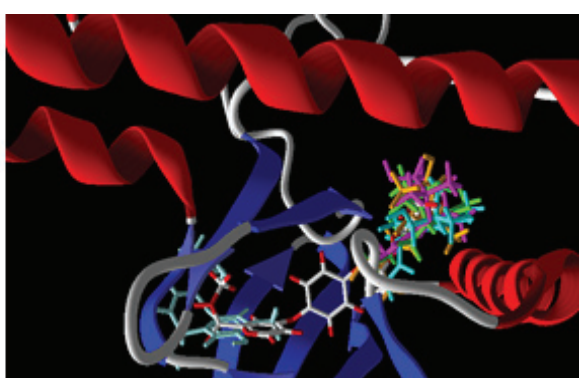

Figure 2. A. The best positions of the five heliannuol compounds against the 3WZE receptor with amino acid residues are shown stick style with ligands indicated by thick lines with fixed color. B. The best positions of the five heliannuol compounds against the 3 WZE receptor. 


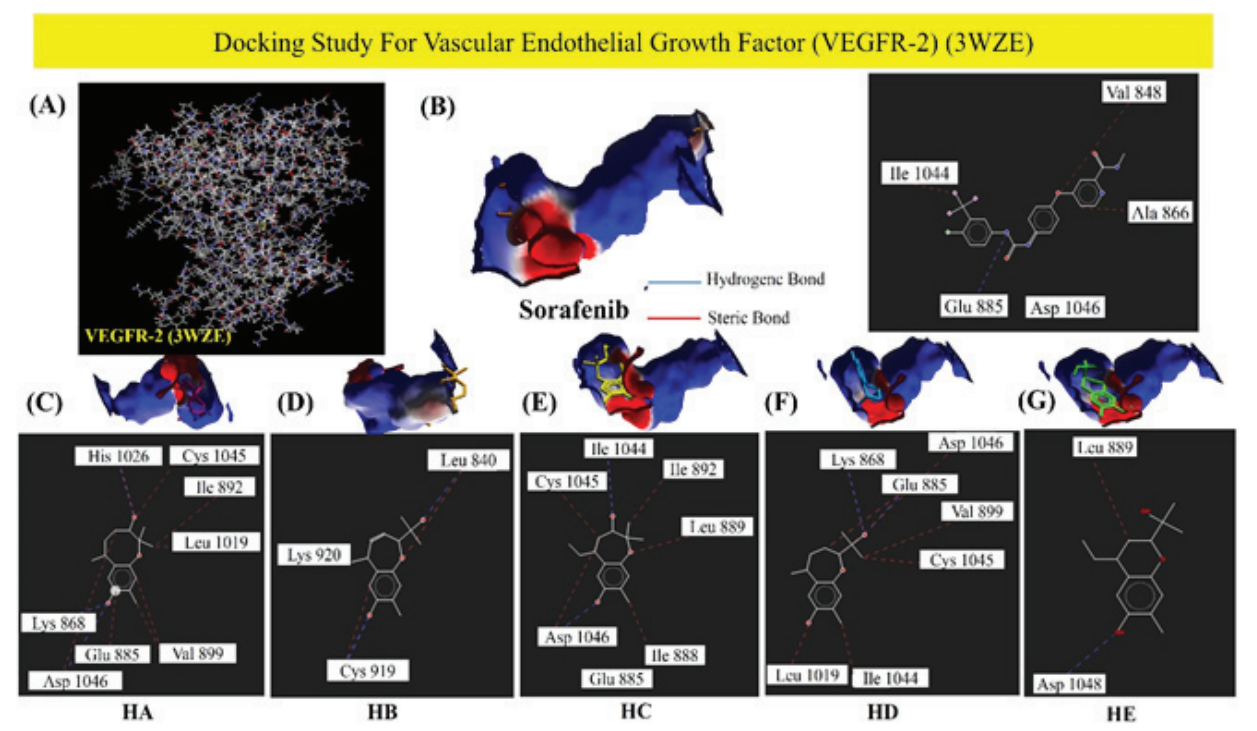

Figure 3. Two dimensions shape of the bond and the best way of the five heliannuol compounds to the 3 WZE receptor with amino acid residues that are indicated by the stick force with the ligands are shown with a thick line with a fixed color; blue lines as hydrogen bond and red lines as steric bond.

$\mathrm{C}=\mathrm{HE}<\mathrm{HA}=\mathrm{HD}$. Molecular weight determines the diffusion ability of a compound penetrate lipid bilayers in cell membranes (Cohen BE, et al., 1996).

The partition coefficient $(\log P)$ is the logarithmic value of the ratio of the solubility of compounds in organic solutions (octanol) to the solubility of compounds in water that determine the lipophilicity properties of a compound (Mannhold, et al., 2009). As a result of the prediction of the Log $\mathrm{P}$, it is found that the compound heliannuol A-E meets Lipinski's RO5, which is less than 5.

The HBA and HBD are other important parameters related to compounds polarity and permeability. According to Lagorce, et al (2017), compounds containing more HBA with less HBD have favorable profile for both these parameters. This is consistent with previously reported papers mentioned that HBD are often the "enemy of medical chemist" (i.e., large number of HBD could be the cause of poor permeability absorbtion and bioavailability) (Baell, et al., 2013). As a result of permeability prediction, the test compound has a value of less than 10 in the HBA and less than 5 in HBD, which means that the heliannuol A-E compound has a good permeability.
As a result of the prediction of the polar surface area (PSA) test in silico, it was found that each heliannuol had a high PSA value, making it possible to penetrate the blood brain barrier moderately. The PSA is a parameter to describe the ability of a compound to penetrate the blood brain barrier, water solubility and toxicity. The PSA is considered low if the PSA value $<75 \AA 2$ and can cause an increase in toxic risk, while PSA $>80 \AA 2$ can penetrate the blood brain barrier (Hughes, 2008).

Prediction of $\mathrm{LD}_{50}$ toxicity as a consequence of, the compound heliannuol A-E is classified as class 4 and 5 with a range of $\mathrm{LD}_{50} 566-1213$ which means it is less toxic. The higher the $\mathrm{LD}_{50}$ value, the lower the toxicity. Class 4 means that the compounds show relatively low toxicity (Rao, 2019). The highest toxicity levels of $\mathrm{HD}>\mathrm{HA}>\mathrm{HC}-$ $=\mathrm{HE}>\mathrm{HB}$ are as follows.

The results of molecular docking in Table 3 shows that the average score of heliannuol E compounds are the smallest values compared to others, namely -75.5164 . This indicates that the compound heliannuol $\mathrm{E}$ has a high affinity and approaches the rerank score of sorafenib as a reference compound. The increasingly negative score indicates 
Table 3. Hydrogen bonding, steric bonding, and rerank score.

\begin{tabular}{|c|c|c|c|}
\hline \multirow[b]{2}{*}{ Compound } & \multirow{2}{*}{$\begin{array}{l}\text { Rerank } \\
\text { Score }\end{array}$} & \multicolumn{2}{|c|}{ Interaction with Amino Acid } \\
\hline & & Hydrogen Interaction & Steric Interaction \\
\hline [HA] & -56.9496 & $\begin{array}{l}\text { Lys } 868(3.10) ; \text { Asp I046 } \\
(2.60) ; \text { Cys I045 ( } 2.8 \mathrm{I}) ; \mathrm{H} \text { is } \\
1026(2.70)\end{array}$ & $\begin{array}{l}\text { Asp I046 (3.19); Glu } 885(3.15) ; \text { Val } 899(2.61 \\
\text { \& } 3.17) \text {; Leu I0I9 (2.82); Ile } 892(3.07) ; \mathrm{H} \text { is } \\
1026 \text { (3.09) }\end{array}$ \\
\hline$[\mathrm{HB}]$ & -70.83646 & $\begin{array}{l}\text { Cys } 919 \text { (3.24 \& 2.60); Leu } 840 \\
(2.63)\end{array}$ & $\begin{array}{l}\text { Lys } 920 \text { (3.0I); Cys } 919 \text { (2.92); Leu } 840 \text { (3.05 \& } \\
3.16)\end{array}$ \\
\hline$[\mathrm{HC}]$ & -61.3292 & $\begin{array}{l}\text { Asp } 1046(3.10) ; \text { lle } 1044 \\
(3.10)\end{array}$ & $\begin{array}{l}\text { Asp } 1046 \text { (3.06); Ile } 888 \text { (3.06); Ile } 892 \text { (2.67); } \\
\text { Leu } 889 \text { (2.72); Cys I045 (3.12) }\end{array}$ \\
\hline$[\mathrm{HD}]$ & -49.61646 & Glu 885 (2.90); Lys 868 (3.0I) & $\begin{array}{l}\text { Leu I } 019 \text { (3.09); Ile I044 (2.98); Cys } 1045 \\
\text { (3.06); Val } 899 \text { (3.I 2); Glu } 885 \text { (2.83); Asp } 1046 \\
(3.16)\end{array}$ \\
\hline$[\mathrm{HE}]$ & -75.5164 & $\begin{array}{l}\text { Asp } 1046(3.10) ; \mathrm{H} \text { is } 1026 \\
(3.42)\end{array}$ & Asp I046 (3.15); Glu 885 (3.13); Leu 889 (2.9I) \\
\hline Sorafenib & -128.0683 & Glu 885 (2.70) & Ile I044 (2.96); Ala 866 (3.16); Val 848 (2.73) \\
\hline
\end{tabular}

a more stable receptor drug binding and predicted better activity, but lower than Sorafenib. Increased activity in the Sorafenib analog compound could be the highest electronegativity value for $\mathrm{F}$ in the halogen community due to electronic effect. In the presence of $3 \mathrm{~F}$, atoms optimize receptor interactions that have an effect on bond stability and behavior. In addition to the Sorafenib there is an urea group (-NHCONH-) which functions as a pharmacophore in the ligand-receptor interaction process, whereas in the heliannuols there are only $\mathrm{OH}$ groups and $\mathrm{C}$ at the aromatic chain (Dai, et al., 2008; Curtin, et al., 2012). The HE $>\mathrm{HB}>\mathrm{HC}>\mathrm{HA}>\mathrm{HD}$ is the largest compound affinity sequence.

According to Temirak, et al. (2012), the key amino acids influence VEGFR-2 (3WZE) receptors, namely Glu885 and Asp1046. In addition to the amino acids Lys868 and Cys919, there is also a typical hydrophobic association in the receptor tyrosine kinase between the aromatic rings of the ligand and the amino acid residues. Without these two main amino acids, the inhibitor effect on the VEGFR-2 receptor will not occur. Sorafenib has 4 interactions at the VEGFR2 receptor. The first interaction is the phenyl urea chain from sorafenib, there is a hydrogen bridge between the glutamate chain and the N-H amide bond from aspartate which is the main key inhibitory activity. The second interaction is called the "selective area", phenyl alanine is formed when it binds to a lipophilic pocket. Because sorafenib has a meta-trifluoromethyl-para-chlorophenyl ring that binds to a hydrophobic pocket. The third interaction is called the "gatekeeper region", the bonds are attractive to aromatic-aromatic interactions involving triphosphate bonds. The fourth interaction is the "hinge area", there is a bond on the aromatic adenine ring and there is a hydrogen bond between the ATP region and the allosteric inhibition region. The N-methyl picolinamide from sorafenib contributes to this interaction.

Based on the docking results of the five Heliannuol compounds, it was found that the heliannuol $\mathrm{A}$, heliannuol $\mathrm{D}$, and heliannuol $\mathrm{E}$ compounds showed the desired results with the interaction of the amino acids Glu885 and Asp1046 according to Table 3 . The three heliannuol compounds namely $\mathrm{A}, \mathrm{D}$, and $\mathrm{E}$ showed interactions according to pharmacophore. Whereas the heliannuol B compounds only bind to the amino acid Cys 919, the heliannuol $\mathrm{C}$ compounds only bind to the amino acid Asp 1046 (Dai, et al., 2008; Curtin, et al., 2012). 


\section{CONCLUSION}

The molecular docking studies show that Heliannuol compounds have fulfilled the five Lipinski laws and possibly possessed low toxicity. Molecular docking simulation showed heliannuol $\mathrm{A}$, heliannuol $\mathrm{D}$, and heliannuol $\mathrm{E}$ compounds interact with VEGFR-2 (PDB ID: 3WZE) as indicated by the interaction with the amino acids Glu885 and Asp1046. However heliannuol and Sorafenib clearly showed different modes of binding and interaction of active site amino acid. Thus, based on previous report, our study also shows good binding capacity of heliannuol compared to the positive drug sorafenib. Therefore, further investigations should be carried out and comfirmed by in silico studies on receptor targets or the observation of other identified therapeutic target and molecular mechanism for future clinical applications.

\section{ACKNOWLEDGEMENT}

The researchers would like to thank Prof. Dr. Siswandono, Apt., M.S., to have links to the Molegro Virtual Docker 5.5 program.

\section{REFERENCES}

Agarwal, S., Hartz, A.M. and Elmquist, W.F., 2011, Breast cancer resistance protein and P-glycoprotein in brain cancer: two gatekeepers team up, Curr Pharm Des., 17(26), 2793-802.

Babeie, G., Aliarab, A., Abroon, S., Rasmi, and Gholizadeh, A., 2018, Application of Sesquiterpene Lactone: a New Promising Way For Cancer Therapy Based on Anticancer Activity, Journal of Biomedicine and Pharmocotheraphy, 106(2), 239-246.

Baell, J., Congreve, M., Leeson, P. and Abad-Zapatero, 2013, Ask the Experts: Past, Present and Future of The RRule of Five, Future Med Chem., 5, 745-752.

Bellettato, C.M. and Scarpa, M., 2018, Possible
Strategies to Cross The Blood Brain Barrier, Italian Journal of Pediatrics, 44(2), 131.

Bell J.S., Koffie, R.M., Rattani, A., Dewan, M.C., Baticulon, R.E., Qureshi, M.M., et al., 2019, Global Incidence of Brain and Spinal Tumors by Geographic Region and Income Level Based on Cancer Registry Data, Journal of Clinical Neuroscience, 66(4), 121-127.

Cohen, B.E. and Bangham, A.D., 1972, Diffusion of small non-electrolytes across liposome membranes, Nature, 236(5343), 173-174.

Conze, D., Weiss, L., Regen, P.S., Bhushan, A., Weaver, D., Johnson, P. and Rincón, M., 2001, Autocrine Production of Interleukin 6 Causes Multidrug Resistance in Breast Cancer Cells, Cancer Research, 61(24), 8851-8858.

Curtin, M.L., Frey, R.R., Heyman, H.R., Soni, N.B., Marcotte, P.A., Pease, L.J., et al., 2012, Thienopyridine ureas as dual inhibitors of the VEGF and Aurora kinase families, Bioorganic \& Medicinal Chemistry Letters, 22(9), 3208-3212.

Dai, Y., Hartandi, K., Soni, N.B., Pease, L.J., Reuter, D.R., Olson, A.M., et al., 2008, Identification of aminopyrazolo-pyridine ureas as potent VEGFR-PDGFR multitargeted kinase inhibitors, Bioorganic \& Medicinal Chemistry Letters, 18(9), 386-390.

Firdausy, Mutiah, R. and Eka, 2020, Predicting Pharmacokinetic Profiles of Sunflower's (Helianthus annuus L.) Active Compounds using in Silico Approach, Journal of Islamic Medicine, 4(1), 1-7.

Heffron, T.P., Wei, B., Olivero, A., Staben, S.T., Tsui, V., Do, S., Dotson, J., et al., 2011, Rational Design of Phosphoinositide 3-Kinase A Inhibitors That Exhibit Selectivity Over the Phosphoinositide 3-Kinase B Isoform, J. Med. Chem, 54(24), 7815-7833.

Jeroen, C.V. and Arie, Z., 2007, Phosphatidylinositol 3-kinase (PI3K) Inhibitors as Anticancer Drugs, Drugs of the Future, 32(6), 537-547.

Kesari, S., 2011, Understanding glioblastoma tumor biology: the potential to improve current diagnosis and treatments, Semin Oncol., 38(Suppl 
4), S2-10.

Knizetova, P., Ehrmann, J., Hlobilkova, A., Vancova, I., Kalita, O., Kolar, Z., and Bartek, J., 2008, Autocrine regulation of glioblastoma cell-cycle progression, viability and radioresistance through the VEGF-VEGFR2 (KDR) interplay, Journal of Cell Cycle, 7(16), 2553-2561.

Kreuger, M.R.O., Grootjans, S., Biavatti, M.W., Vandenabeele, P. and D'Herde, K., 2012, Sesquiterpene lactones as drugs with multiple targets in cancer treatment: focus on parthenolide, Anticancer Drugs, 23(9), 883-896.

Kuntala, N., Telu, J., Anireddy, J., and Pal, S., 2017, A Brief Overview on Chemistry and Biology of Benzoxepine, Letters in Drug Design \& Discovery, 14(1), 1-13.

Lipinski, C.A., Lombardo, F., Dominy, B.W. and Feeney, P.J., 2001, Experimental and Computational Approaches to Estimate Solubility and Permeability in Drug Discovery and Development Settings, Advanced Drug Delivery Reviews, 46(18), 3-26.

Logarce, D., Domino, D., Maria, A. and Bruno, 0. 2017, Computational Analysis of Calculated Physicochemical and ADMET Properties of Pretein-protein Interaction Inhibitor, Scientific Report, 7, 46277.

Mannhold, R., Poda, G,I., Ostermann, C. and Tetko, I.V., 2009, Calculation of Molecular Lipophilicity: State of the Art and Comparation of Log P Methods on More Than 96.000 Compounds, Journal of Pharmaceutical Science, 98(3), 861-89. Ministry of Health, 2017, The National Guideline for
Medical Service: Brain Tumor, Jakarta: Indonesian Health Office.

Nico, B. and Ribatti, D., 2012, Morphofunctional aspects of the blood-brain barrier, Curr Drug Metab., 13(1), 50-60.

Paterson, D.A., Conradi, R.A., Hilgers, A.R., Vidmar, T.J. and Burton, P.S., 1994, A nonaqueous partitioning system for predicting the oral absorption potential of peptides, Quant. Struct.-Act. Relat, 13(1), 4-10.

Pires, D.E.V., Bllundell, T.L. and Ascher, D.B., 2015, pkCSM: Predicting Small-Molecule Pharmacokinetic and Toxicity Properties Using Graph-Based Signatures, Journal of Medicinal Chemistry, 58(9), 4066-4072.

Pollastri, M.P., 2010, Overview on The Rule of Five, Current Protocols in Pharmacology, 9(12), 1-9.

Pratama, 2015, Penambatan Molekuler senyawa aktif Temulawak (Curcuma xantoriza) dengan enzim COX-2 sebagai kandidat Obat Anti Kanker Payudara, Bogor: IPB.

Rao, B.S, 2019, Understanding the Globally Harmonized System of Classification and Labeling of Chemical Yhe Purple Book, International Journal of Drug Regulatory Affairs, 7(2), 7-16.

Talo, M., Baloglu, U.B., Yıldırım, O., and Acharya, U.R., 2019, Application of Deep Transfer Learning for Automated Brain Abnormality Classification Using Mr Images, Cognitive Systems Research, 54(24), 176-188.

Temirak, Mona, and Mahmoud, 2012, Anti-Cancer Agent in Medicine Chemistry, 12(1). 